\title{
Clinical and epidemiological features of amyotrophic lateral sclerosis in eastern Turkey
}

\author{
@Recep Yevgi, @Nuray Bilge \\ Atatürk University, Faculty of Medicine, Department of Neurology, Erzurum, Turkey
}

Cite this article as: Yevgi R, Bilge N. Clinical and epidemiological features of amyotrophic lateral sclerosis in eastern Turkey. J Health Sci Med 2021; 4(5): 576-581.

\begin{abstract}
Aim: The number of studies on the epidemiological and clinical data of amyotrophic lateral sclerosis (ALS) patients in Turkey is quite low and the studies on this subject reflect the data of western regions of Turkey. In this study, we aimed to present the demographic, clinical and mortality features of ALS patients diagnosed in the last 10 years in a large reference hospital in the Eastern Anatolia region of Turkey.

Material and Method: 42 ALS patients diagnosed between January 2011 and January 2021 in Atatürk University, Faculty of Medicine, Department of Neurology were included in the study. The data of the patients were obtained by retrospectively scanning the patient electronic files registered in the database of our hospital. The age, gender, examination findings, clinical course, treatments they received and the cause of death of the patients were recorded.

Results: 26 of ALS patients were men and 16 were women. The mean age of onset was $53.4 \pm 12.3$ and the mean diagnostic delay was $13.6 \pm 6.9$ months. $64.2 \%$ of the patients had onset in the spinal region, and $35.7 \%$ in the bulbar region. Weakness/atrophy of the upper extremity muscles and swallowing difficulty were the most common onset symptoms. All ALS patients were using riluzole. 11 ALS patients died. The mean time between diagnosis and death in patients who died was $27.2 \pm 18.6$ months. The most common causes of death in ALS patients were pneumonia and sepsis.

Conclusion: Age of onset of ALS was low in our patients. The number of patients in the clinically definite ALS group was the highest. Weakness/atrophy of the upper extremity muscles and swallowing difficulty were the most common onset symptoms. Approximately $2 / 3$ of the patients had spinal, and 1/3 bulbar region onset. There was no significant difference between spinal and bulbar onset patients in terms of gender, age of disease onset, mortality, and life expectancy of patients with death. The rate of using riluzole was high. The most common causes of death in ALS patients were pneumonia and sepsis.
\end{abstract}

Keywords: Amyotrophic lateral sclerosis, epidemiology, clinical, eastern, Turkey, mortality

\section{INTRODUCTION}

Amyotrophic lateral sclerosis (ALS), also known as motor neuron disease, is a progressive disease that causes muscle weakness as a result of the degeneration of upper and lower motor neurons. Although ALS is a disease described in 1869, its cause and pathogenesis are still largely unknown and there is currently no definitive treatment (1). The incidence of ALS is $0.4-3 / 100,000$ and its prevalence is 3-8/100.000 (2). Clinical findings usually start at the age of 50-60. Approximately 5-10\% of all ALS cases are familial and $90-95 \%$ are sporadic ALS $(3,4)$.

Clinical findings in patients with ALS consist of lower motor neuron findings such as asymmetric weakness in arm and leg muscles, atrophy, fasciculation, dysphasia, and swallowing difficulty, as well as upper motor neuron findings such as hyperreflexia and spasticity that occur as a result of degeneration of the lateral corticospinal tracts in the spinal cord.

The diagnosis of ALS is made as a result of the patient's history, physical examination findings, and data obtained through electrophysiological tests. Sometimes neuroimaging methods, blood tests, genetic studies and rarely muscle biopsy may be required to exclude other possible diagnoses. Revised El-Escorial diagnostic criteria defined by Brooks et al. in 2000 are used in the diagnosis of ALS (5).

ALS is a chronic, progressive, and mortal disease, and long-term and detailed follow-up of patients with ALS is significant. 
The number of studies on the epidemiological and clinical data of ALS patients in Turkey is quite low and the studies on this subject mostly reflect the data of western regions of Turkey. In our study, we aimed to present the demographic, clinical and mortality features of ALS patients diagnosed in the last 10 years in a large reference hospital in the Eastern Anatolia region of Turkey.

\section{MATERIAL AND METHOD}

Ethics committee approval was obtained from Atatürk University Faculty of Medicine, Clinical Research Ethics Committee (Date: 15.04.2021, Decision No: 183). All procedures were carried out in accordance with the ethical rules and the principles of the Declaration of Helsinki.

Forty-two ALS patients diagnosed between January 2011-January 2021 in the Department of Neurology clinic, Faculty of Medicine, Atatürk University were included in the study. The data of the patients were obtained by retrospectively scanning the patient electronic files registered in the database of our hospital. ALS diagnosis was made according to the revised ElEscorial criteria to the patients. Electromyography (nerve conduction studies and needle electromyography) and spinal magnetic resonance imaging were performed in all patients. Conditions included in the differential diagnosis of ALS such as myelopathy, multifocal motor neuropathy, paraneoplastic syndrome, and infection were excluded by appropriate laboratory and imaging methods. Diagnosed ALS patients were followed up clinically at 3-6 month intervals. At each control examination or hospital admission, patients were reevaluated in terms of revised El-Escorial criteria and electrophysiologically, and the patients' examination findings, clinical course, treatments, gastrostomy, tracheostomy, and cause of death were recorded. Patients who were out of followed up for various reasons over time were not included in the study.

\section{Statistical Analysis}

Study data were analysed by using SPSS 22 (Statistical Package for the Social Sciences) program. Data compliance for normal distribution was evaluated with the Kolmogorov Smirnov test. Chi-Square test was used in the analysis of categorical data between the groups, and the Mann Whitney $\mathrm{U}$ test was used in the analysis of numerical data that did not comply with normal distribution. Statistical significance level was accepted as $\mathrm{p}<0,05$. Descriptive statistics such as age, gender, onset region, onset symptoms were calculated as mean, standard deviation, range, and percentage.

\section{RESULTS}

$26(61.9 \%)$ of ALS patients were male, and 16 (38.1\%) were female. The male/female rate was in favor of the male gender with 1,62. Mean age of onset was $54 \pm 10.7$ in male patients; $52.5 \pm 14.8$ in female patients. The mean diagnostic delay from the onset of symptoms to diagnosis in ALS patients was $13.6 \pm 6.9$ months. There was no statistically significant difference between male and female patients in terms of mean age of onset and diagnostic delay $(p>0.05)$. Detailed distribution of patients by age and gender is shown in Table 1. 64.2\% of the patients had onset in the spinal region, and $35.7 \%$ in the bulbar region. No statistically significant difference was found between spinal and bulbar-onset patients in terms of gender, age of disease onset, mortality and life expectancy of patients with death $(\mathrm{p}>0.05)$ (Table $2)$. Weakness/atrophy of upper extremity muscles and swallowing difficulty were the most common onset symptoms at first admission (Table 3). According to the revised El-Escorial criteria, the number of patients in the clinically definite and probable ALS groups was in the majority (Table 3). All ALS patients were using riluzole and only 2 patients were receiving speech therapy (Table 3). 11 ALS patients died. The mean time between diagnosis and death in patients who died was $27.2 \pm 18.6$ months. No statistically significant difference was found between male and female patients in terms of the time between diagnosis and death and the average age of the patients who died ( $p>0.05)$. The most common causes of death in ALS patients were pneumonia and sepsis (Table 4).

\begin{tabular}{|c|c|c|c|c|}
\hline $\begin{array}{l}\text { Characteristics } \\
\text { of the patients }\end{array}$ & $\begin{array}{l}\text { Total } \\
\text { n (\%) }\end{array}$ & $\begin{array}{c}\text { Female } \\
\text { n (\%) }\end{array}$ & $\begin{array}{l}\text { Male } \\
\text { n (\%) }\end{array}$ & $\mathbf{p}$ \\
\hline Number & $42(100)$ & $16(38.1)$ & $26(61.9)$ & - \\
\hline \multicolumn{5}{|l|}{ Age groups } \\
\hline $20-29$ & $2(4.8)$ & $1(2.4)$ & $1(2.4)$ & - \\
\hline $30-39$ & 5 (11.9) & $1(2.4)$ & $4(9.5)$ & - \\
\hline $40-49$ & $8(19)$ & $5(11.9)$ & $3(7.1)$ & - \\
\hline $50-59$ & $10(23.8)$ & $3(7.1)$ & $7(16.7)$ & - \\
\hline $60-69$ & $15(35.7)$ & $4(9.5)$ & $11(26.2)$ & - \\
\hline $70-79$ & $2(4.8)$ & $2(4.8)$ & - & - \\
\hline $\begin{array}{l}\text { Disease duration; } \\
\text { (Month, mean } \pm S D ; \\
\text { median (min-max)) }\end{array}$ & $\begin{array}{l}66.9 \pm 45.4 \\
52(5-192)\end{array}$ & $\begin{array}{l}63.6 \pm 45.5 \\
48(9-121)\end{array}$ & $\begin{array}{l}68.9 \pm 46.1 \\
58(5-192)\end{array}$ & $0.659^{*}$ \\
\hline $\begin{array}{l}\text { Mean age of disease } \\
\text { onset } \\
(\text { mean } \pm S D ; \text { median } \\
(\text { min-max })\end{array}$ & $\begin{array}{l}53.4 \pm 12.3 \\
54(27-78)\end{array}$ & $\begin{array}{c}52.5 \pm 14.8 \\
52.5(27-78)\end{array}$ & $\begin{array}{c}54 \pm 10.7 \\
54(29-68)\end{array}$ & $0.487^{\star}$ \\
\hline $\begin{array}{l}\text { Diagnostic delay } \\
(\text { Month, mean } \pm S D ; \\
\text { median }(\text { min-max }) \text { ) }\end{array}$ & $\begin{array}{c}13.6 \pm 6.9 \\
12.5(4-40)\end{array}$ & $\begin{array}{c}12.7 \pm 5.3 \\
12.5(4-22)\end{array}$ & $\begin{array}{c}14.2 \pm 7.7 \\
12.5(4-40)\end{array}$ & $0.688^{\star}$ \\
\hline
\end{tabular}




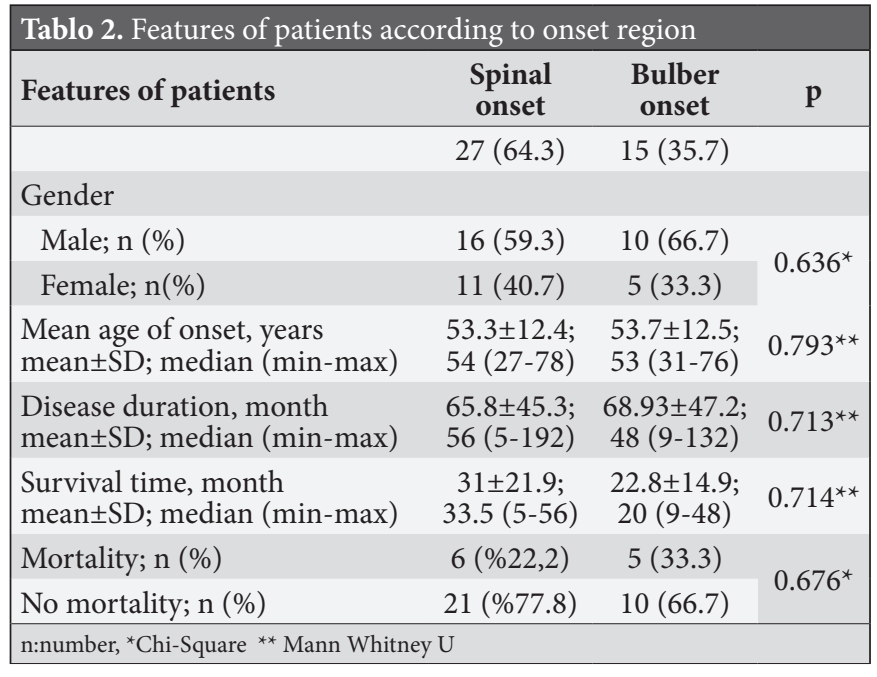

\section{DISCUSSION}

It is known that male gender is a risk factor for ALS.6 Male / female (M/F) rate in ALS patients varies between 1-3 in many studies (6-11). In studies conducted in Antalya province and Thrace region in Turkey, this rate was found as 1.78 and $2(8,9)$. The M/F rate was found to be close to these values with 1.62 .

When it is examined at the mean age of onset of ALS, different results are obtained in a wide range of age. The mean age of onset of ALS has been reported as 56 and 60 , respectively, in Russia and Greece, Turkey's northern and western neighbors $(10,11)$. The mean age of onset of ALS in Turkey was reported as $\mathbf{5 6}$ and 58 in two different studies conducted in the western regions of Turkey $(8,9)$.

\begin{tabular}{|c|c|c|c|c|}
\hline & Total (n:42, \%) & Female (n:16, \%) & Male (n:26, \%) & $\mathbf{p}$ \\
\hline \multicolumn{5}{|l|}{ Symptoms } \\
\hline Weakness/atrophy of the upper extremity muscles & $31(73.8)$ & $13(81.3)$ & $18(69.2)$ & $0.390^{*}$ \\
\hline Weakness/atrophy of the lower extremity muscles & $14(33.3)$ & $4(25.0)$ & $10(38.5)$ & $0.369^{*}$ \\
\hline Fasciculation & $15(35.7)$ & $4(25.0)$ & $11(42.3)$ & $0.256^{*}$ \\
\hline Swallowing difficulty & $20(47.6)$ & $7(43.8)$ & $13(50.0)$ & $0.694^{*}$ \\
\hline Aphasia & $15(35.7)$ & $6(37.5)$ & $9(34.6)$ & $0.850^{*}$ \\
\hline Other & $18(42.9)$ & $11(68.8)$ & $7(26.9)$ & $0.008^{*}$ \\
\hline Weigh loss & $7(16.6)$ & $4(9.5)$ & $3(7.1)$ & \\
\hline Cramp & $4(9.5)$ & $3(7.1)$ & $1(2.4)$ & \\
\hline Aphonia & $4(9.5)$ & $3(7.1)$ & $1(2.4)$ & \\
\hline Dementia & $3(7.1)$ & $1(2.4)$ & $2(4.7)$ & \\
\hline \multicolumn{5}{|l|}{ ALS patients according to the revised El Escorial Criteria } \\
\hline Clinically definite ALS & $19(45.2)$ & $6(14.3)$ & $13(30.9)$ & - \\
\hline Clinically probable ALS & $15(35.7)$ & $6(14.3)$ & $9(21.4)$ & - \\
\hline Laboratory-supported probable ALS & $6(14.3)$ & $3(7.1)$ & $3(7.1)$ & \\
\hline Clinically possible ALS & $2(4.8)$ & $1(2.4)$ & $1(2.4)$ & - \\
\hline \multicolumn{5}{|l|}{ Treatments } \\
\hline Riluzole & $42(100)$ & $16(38.1)$ & $26(61.9)$ & - \\
\hline Vitamin (B complex, vitamin C, vitamin E) & $16(38.1)$ & $5(11.9)$ & $11(26.2)$ & - \\
\hline Physical therapy and rehabilitation & $19(45.2)$ & $8(19)$ & $11(26.2)$ & - \\
\hline Speech therapy & $2(4.8)$ & $1(2.4)$ & $1(2.4)$ & - \\
\hline Gastrostomy & $10(23.8)$ & $3(7.1)$ & $7(16.6)$ & - \\
\hline Tracheotomy & $11(26.2)$ & $5(11.9)$ & $6(14.3)$ & - \\
\hline
\end{tabular}

\section{Table 4. Characteristics of ALS patients who died}

\begin{tabular}{|c|c|c|c|c|}
\hline ALS Patients & Female (n, \%) & Male (n, \%) & Total (n, \%) & $\mathbf{p}$ \\
\hline Mortality & $5(45.4)$ & $6(54.6)$ & $11(100)$ & $0.987^{*}$ \\
\hline Age $($ mean $\pm S D ;$ median $(\min -\max )$ & $52.6 \pm 14.5 ; 55(31-66)$ & $62.1 \pm 5.4 ; 64(55-67)$ & $57.8 \pm 11.1 ; 62(31-67)$ & $0.141^{* *}$ \\
\hline $\begin{array}{l}\text { Time between ALS diagnosis and death } \\
\text { (mean } \pm \text { SD;median (min-max) }\end{array}$ & $21.4 \pm 15.7 ; 20(9-48)$ & $32.1 \pm 20.834 .5(5-56)$ & $27.2 \pm 18.6 ; 20(5-56)$ & $0.409^{* *}$ \\
\hline Spinal onset & $3(27.3)$ & $3(27.3)$ & $6(54.5)$ & \\
\hline Bulbar onset & $2(18.2)$ & $3(27.3)$ & $5(45.5)$ & \\
\hline \multicolumn{5}{|l|}{ Cause of seath } \\
\hline Pneumonia & $2(18.1)$ & $4(36.3)$ & $6(54.4)$ & \\
\hline Sepsis & $1(9.1)$ & $1(9.1)$ & $2(18.2)$ & \\
\hline Pulmonary embolism & $1(9.1)$ & - & $1(9.1)$ & \\
\hline Coronary failure & - & $1(9.1)$ & $1(9.1)$ & \\
\hline Cerebrovascular Disease & $1(9.1)$ & - & & \\
\hline
\end{tabular}


In our study, the mean age of onset of ALS patients was found to be $53.4 \pm 12.3$, and this value showed that the mean age of onset of ALS in our patients was lower when compared to the results of two other studies conducted in Turkey. It is known that $5-10 \%$ of all ALS cases are familial and the age of onset is about 10 years earlier in the familial form of ALS $(12,13)$. We think that the higher rate of consanguineous marriage in our region compared to the western regions of Turkey where other studies have been conducted may have played a role in this result. Although genetic screening has not been performed on our patients, the fact that more than $1 / 3$ of our patients are under the age of 50 supports the opinion that the number of patients with familial form is high.

The incidence of ALS increases every decade particularly after the age of 40 , peaks at the age of 74 and then reduces. 2 The peak incidence of ALS onset is between 60 and 75 years in most studies (14). $40.5 \%$ of our ALS patients were between the ages of 60-79 and they confirmed this situation.

ALS is a disease that is diagnosed clinically, and its onset symptoms may require differential diagnosis with many diseases. The lack of sufficient biomarkers specific to the clinically used disease and the need to demonstrate progressive spread of the disease in some cases may lead to delay in the diagnosis of ALS. The mean delay between the onset of ALS symptoms and diagnosis was 13.6 \pm 10.9 months. This period is specified between 9-24 months in many studies $(8,15-17)$. Results regarding the distribution of onset symptoms have been reported to be contradictory in different studies. In some studies, the most common initial symptom in ALS patients was reported as upper extremity weakness, while in some studies, on the other hand, it was reported as lower extremity weakness $(11,18,19)$. In a study conducted in England, it was reported that the symptoms in $44 \%$ of the motor neuron patients start from the upper extremity, in $37 \%$ from the lower extremity, $74 \%$ have upper extremity weakness and $60 \%$ have lower extremity weakness. In the same study, swallowing difficulty was found in $41 \%$ of the patients, and dysphasia was found in $23 \%(20)$. Weakness/atrophy of the upper extremity muscles $(73.8 \%)$ was the most common onset symptom in patients, followed by swallowing difficulty with $47.6 \%$ and dysphasia with $35.7 \%$.

When patients are classified according to the ElEscorial criteria, the distribution of patients varies in different studies. In a study conducted in Italy, $45 \%$ of the patients were clinically definite, $27 \%$ were clinically probable ALS; in another study conducted in Sicily, 20\% of the patients were evaluated in the clinically definite and $49.4 \%$ in the clinically probable ALS group $(21,22)$.
In studies conducted in Turkey, these rates are $60 \%$ and $75.6 \%$ for clinically definite ALS, and it was determined as $24.8 \%$ and $11 \%$ for clinically probable ALS $(8,9)$. $45.2 \%$ of our patients were in the clinically definite ALS group, and $35.7 \%$ were in the clinically probable ALS group. While our rate of patients in the clinically probable ALS group was higher than these studies, our rate of clinically definite ALS was low.

In a study conducted in China, it was found that $32.3 \%$ of ALS patients used riluzole, $40.3 \%$ used vitamins, and $11.3 \%$ used conventional Chinese treatments (23). The rate of use of riluzole in ALS patients was 53.6\% in Korea, $60.7 \%$ in Taiwan, and $86.3 \%$ in Germany (24-26). All of our patients were using riluzole and this rate of use was quite high compared to many countries. ALS treatment is not covered by insurance, or solely clinically definite and probable ALS patients are covered by insurance in some countries, however there is no such limitation in riluzole transportation in our country, which we think this led to this different result. Once more, in a study with a high number of patients, it was stated that $76.1 \%$ of ALS patients received motor rehabilitation and 25.2\% received speech therapy (27). It was noteworthy that nearly half of our patients did not benefit from physical therapy and rehabilitation facilities, and the number of patients receiving speech therapy was very low.

The life expectancy from the onset of ALS to death varies between 24 and 71 months in various studies $(23,28)$. While this period is generally longer in Asian countries, it appears to be shorter in European countries (28). Life expectancy in ALS varies depending on many factors. While conditions such as male gender, late onset age, short diagnostic delay, bulbar onset, low body mass index, exposure to pesticides, living in rural areas are associated with poor prognosis, factors such as female gender, opening tracheostomy, use of riluzole are associated with better prognosis $(23,29-31)$. The life expectancy from the onset of ALS symptoms to death ranged from 5 to 56 months, however the average was 27 months. This period was similar to European countries. No statistically significant difference was found between gender and onset region and life expectancy. The low number of patients who died may have played a role in this different result.

In a post-mortem study conducted by Corcia et al.(32) on ALS patients, they found that the most common causes of death in ALS patients were bronchopneumonia (55\%) and aspiration pneumonia (16\%). In our study, the most common causes of death in ALS patients were determined as pneumonia and sepsis, and it was consistent with the results of this study. 


\section{CONCLUSION}

The low age of onset of ALS in our patients and the fact that $35.7 \%$ of the patients are under the age of 50 support the opinion that the familial form of ALS may be more in our region. The number of patients in the clinically definite ALS group according to the El-Escorial criteria was the highest. Weakness/atrophy of the upper extremity muscles was the most common onset symptom in our patients, followed by difficulty in swallowing and dysphasia. Approximately $2 / 3$ of the patients had spinal, and $1 / 3$ bulbar region onset. There was no significant difference between spinal and bulbar onset patients in terms of gender, age of disease onset, mortality, and life expectancy of patients with death. The number of patients using Riluzole is high; the number of patients who received physical therapy and speech therapy was low. The most common cause of death in ALS patients were identified as pneumonia and sepsis. This study has some limitations, including the small number of patients and the lack of genetic testing for ALS patients.

\section{ETHICAL DECLARATIONS}

Ethics Committee Approval: Ethics committee approval was obtained from the Atatürk University, Faculty of Medicine, Clinical Research Ethics Committee (Date: 15.04.2021, Decision No: 183).

Informed Consent: Because the study was designed retrospectively, no written informed consent form was obtained from patients.

Referee Evaluation Process: Externally peer-reviewed.

Conflict of Interest Statement: The authors have no conflicts of interest to declare.

Financial Disclosure: The authors declared that this study has received no financial support.

Author Contributions: All of the authors declare that they have all participated in the design, execution, and analysis of the paper, and that they have approved the final version.

\section{REFERENCES}

1. Charcot JMJ. A. Deux cas d'atrophie musculaire progressive avec lesions de la substance grise et des faisceaux antero-lateraux de la moelle epiniere [French]. Arch Physiol Neurol Pathol 1869; 2: 744.

2. Worms PM. The epidemiology of motor neuron diseases: a review of recent studies. J Neurol Sci 2001; 191: 3.

3. Byrne S, Walsh C, Lynch C, et al. Rate of familial amyotrophic lateral sclerosis: a systematic review and meta-analysis. J Neurol Neurosurg Psychiatry 2011; 82: 623-7.

4. Taylor JP, Brown RH Jr, Cleveland DW. Decoding ALS: from genes to mechanism. Nature 2016; 539: 197.

5. Brooks BR, Miller RG, Swash M, Munsat TL. El Escorial revisited: revised criteria for the diagnosis of amyotrophic lateral sclerosis. Amyotrophic lateral sclerosis and other motor neuron disorders: official publication of the World Federation of Neurology, Research Group on Motor Neuron Diseases 2000; 1: 293-9.
6. Manjaly ZR, Scott KM, Abhinav $K$, et al. The sex ratio in amyotrophic lateral sclerosis: A population based study. Amyotroph Lateral Scler 2010; 11: 439-42.

7. Luna J, Diagana M, Ait Aissa L, et al. Clinical features and prognosis of amyotrophic lateral sclerosis in Africa: the TROPALS study. J Neurol Neurosurg Psychiatry 2019; 90: 20-9.

8. Turgut N, Varol SaraÇoglu G, Kat S, et al. An epidemiologic investigation of amyotrophic lateral sclerosis in Thrace, Turkey, 2006-2010. Amyotroph Lateral Scler Frontotemporal Degener 2019; 20: 100-6.

9. Uysal H, Taghiyeva P, Türkay M, Köse F, Aktekin M. Amyotrophic lateral sclerosis in Antalya, Turkey. A prospective study, 20162018 [published online ahead of print, 2020. Amyotroph Lateral Scler Frontotemporal Degener 2020; 1-7.

10. Brylev L, Ataulina A, Fominykh V, et al. The epidemiology of amyotrophic lateral sclerosis in Moscow (Russia). Amyotroph Lateral Scler Frontotemporal Degener 2020; 21: 410-5.

11. Argyriou AA, Polychronopoulos P, Papapetropoulos S, et al. Clinical and epidemiological features of motor neuron disease in south-western Greece. Acta Neurol Scand 2005; 111: 108-13.

12.Li TM, Alberman E, Swash M. Comparison of sporadic and familial disease amongst 580 cases of motor neuron disease. J Neurol Neurosurg Psychiatry 1988; 51: 778-84.

13. Camu W, Khoris J, Moulard B, et al. Genetics of familial ALS and consequences for diagnosis. French ALS Research Group. J Neurol Sci 1999; 165 Suppl 1: 21-6.

14. Chiò A, Logroscino G, Traynor BJ, et al. Global epidemiology of amyotrophic lateral sclerosis: a systematic review of the published literature. Neuroepidemiology 2013; 41: 118-30.

15.Longinetti E, Wallin AR, Samuelson K, et al. The Swedish motor neuron disease quality registry. Amyotroph Lateral Scler Frontotemporal Degener 2018; 19: 528-37.

16. Leighton DJ, Newton J, Stephenson LJ, et al. Changing epidemiology of motor neurone diseases in Scotland. J Neurol 2019; 266: 817-25.

17. Aktekin MR, Uysal H. Epidemiology of Amyotrophic Lateral Sclerosis. Turk J Neurol 2020; 26: 187-96

18. Haverkamp LJ, Appel V, Appel SH. Natural history of amyotrophic lateral sclerosis in a database population. Validation of a scoring system and a model for survival prediction. Brain 1995; 118: 707-19.

19.Piemonte and Valle d'Aosta Register for Amyotrophic Lateral Sclerosis (PARALS). Incidence of ALS in Italy: evidence for a uniform frequency in Western countries. Neurology 2001; 56: 239-44.

20. Li TM, Alberman E, Swash M. Clinical features and associations of 560 cases of motor neuron disease. J Neurol Neurosurg Psychiatry 1990; 53: 1043-5.

21.Beghi E, Millul A, Micheli A, Vitelli E, Logroscino G; SLALOM Group. Incidence of ALS in Lombardy, Italy. Neurology 2007; 68: 141-5.

22. Ragonese P, Cellura E, Aridon P, et al. Incidence of amyotrophic lateral sclerosis in Sicily: A population based study. Amyotroph Lateral Scler 2012; 13: 284-7.

23..Chen L, Zhang B, Chen R, et al. Natural history and clinical features of sporadic amyotrophic lateral sclerosis in China. J Neurol Neurosurg Psychiatry 2015; 86: 1075-81.

24. Jun KY, Park J, Oh KW, et al. Epidemiology of ALS in Korea using nationwide big data. J Neurol Neurosurg Psychiatry 2019; 90: 395403.

25. Lee CT, Chiu YW, Wang KC, et al. Riluzole and prognostic factors in amyotrophic lateral sclerosis long-term and short-term survival: a population-based study of 1149 cases in Taiwan. J Epidemiol 2013; 23: 35-40.

26. Dorst J, Chen L, Rosenbohm A, et al. Prognostic factors in ALS: a comparison between Germany and China. J Neurol 2019; 266: 1516-25. 
27. Kacem I, Sghaier I, Bougatef S, et al. Epidemiological and clinical features of amyotrophic lateral sclerosis in a Tunisian cohort. Amyotroph Lateral Scler Frontotemporal Degener 2020; 21: 1319.

28. Marin B, Logroscino G, Boumediene F, et al. Clinical and demographic factors and outcome of amyotrophic lateral sclerosis in relation to population ancestral origin. Eur J Epidemiol 2016; 31: 229-45.

29. Louwerse ES, Visser CE, Bossuyt PM, Weverling GJ. Amyotrophic lateral sclerosis: mortality risk during the course of the disease and prognostic factors. The Netherlands ALS Consortium. J Neurol Sci 1997; 152 Suppl 1:10-7.

30. Chiò A, Logroscino G, Hardiman O, et al. Prognostic factors in ALS: A critical review. Amyotroph Lateral Scler 2009; 10: 310-23.

31.Stevic Z, Kostic-Dedic S, Peric S, et al. Prognostic factors and survival of ALS patients from Belgrade, Serbia. Amyotroph Lateral Scler Frontotemporal Degener 2016; 17: 508-14.

32. Corcia P, Pradat PF, Salachas F, et al. Causes of death in a postmortem series of ALS patients. Amyotroph Lateral Scler 2008; 9 : $59-62$. 